\title{
Study on Grinding of Titanium Alloy with Electrostatic Spraying Coating Wheel
}

\author{
WANG Xiaowei ${ }^{\mathrm{a}}$, HUO Wenguo ${ }^{\mathrm{b}}, \mathrm{CAl}$ Lanrong $^{\mathrm{c}}$ \\ Tianjin Key Laboratory of High Speed Cutting \& Precision Machining, Tianjin University of \\ Technology and Education, Tianjin 300222, China \\ axuanhualaomao@163.com, b wghuo@163.com, ${ }^{\text {CC }}$ ailr2003@163.com
}

Keywords: Electrostatic Spraying; Coating Grinding Wheel; Titanium Alloy; Grinding Temperature;

\begin{abstract}
Plenty of grinding heat will generate in the process of grinding titanium alloy, it will lead grinding burn easily, and finally affect the surface quality of the workpiece. As a result, it is usually to use a lot of grinding fluid in the traditional grinding to reduce the temperature of the grinding, but slathering grinding fluid brings great harm to the health of workers and to the environment, and increasing costs. Based on the idea of the "solid lubricant instead of grinding fluid," an intelligent online electrostatic spraying grinding wheel adaptive lubrication coating system device was prepared and carried out dry grinding experiment of titanium alloy. Experiment shows: the system can obtain homogeneous structure of grinding wheel lubrication coating, as a result, the problem of grinding burn in the process of dry grinding titanium alloy can be effectively solved.
\end{abstract}

\section{Introduction}

Titanium alloy has many advantages, such as high strength, light weight, corrosion resistance, etc, so it is widely used in the aerospace industry, oil industry, biological medicine and chemical industry and so on. However, due to its low heat conductivity, prone to the phenomenon of grinding burn in the process of grinding, affecting the surface of the workpiece quality. It is usually to use a lot of grinding fluid in the traditional grinding to reduce the temperature of the grinding, but slathering grinding fluid brings great harm to the health of workers and to the environment[1-4].In order to solve the mentioned problems, it is imperative to adopt a new technology that combine environmental with economic green grinding. Based on green machining technology ideas" solid lubricant instead of grinding fluid", intelligent electrostatic coating system for wheel lubricating coating is developed. The basic principle is to apply the solid lubricant to the surface of the grinding wheel through the online intelligent spraying system with controllable parameters in the process of grinding, finally a lubricating film is formed between the abrasive particles and the workpiece. As a result, it can reduce the friction coefficient between the wear particle and the surface of the workpiece, reduce friction force, reduce the generation of grinding heat, so as to reduce the grinding temperature. [5-6].Graphite is Choose as the solid lubricant powder, coating it on CBN grinding wheel's surface, and doing the TC4 titanium alloy grinding experiment. Analysis of the grinding temperature under different cooling conditions is to research on effective methods of coating grinding wheel grinding titanium alloy.

\section{Finite element simulation analysis based on DEFORM-3D}

In the actual machining process, measuring the grinding temperature of the workpiece are quite complicated, related to the elastic-plastic theory, metal physics, heat transfer and other disciplines areas. It is difficult to study the grinding mechanism thoroughly through simply experimental data. In this paper, the process of the grinding of the titanium alloy by the grinding wheel dry grinding is studied by DEFORM-3D finite element simulation software. The simulation of the process of the titanium alloy with the dry grinding of the coated grinding wheel and the uncoated grinding wheel is carried out respectively, and compare the temperature of the two grinding wheel. After the simulation, compared with the real grinding test, in order to realize the purpose of the feasibility of DEFORM-3D finite element simulation software in the process of dry grinding titanium alloy and 
optimize process parameters.

\section{The establishment of simulation geometry model}

The geometrical parameters of the cutting edge of the abrasive grains can be defined according to the geometrical parameters of the cutting tools. For example, the rake angle, the back angle, the top cone angle, the grinding edge radius and other parameters. Abrasive cutting edge parameters affect the sharp degree and the cutting ability of grinding wheel. The grinding edge of the wear debris is different, the outstanding height is also vary greatly, and from the macro perspective, the shape of the grinding wheel is approximate to irregular polyhedron. But in order to simplify the research, the cutting edge of a variety of abrasive grains can be simplified into an idealized shape. In this paper, the single particle abrasive particles are simplified to a conical conical tip with a blunt circle. The parameters of the conical abrasive grain are: the tip blunt circle radius $r_{\mathrm{g}}=0.014 \mathrm{~mm}$, the conical top cone angle $2 \Theta=104^{\circ}$, the conical bottom diameter $\mathrm{d}=0.18 \mathrm{~mm}$. Simplify the workpiece to the rectangular parts, and dimensions are $2 \mathrm{~mm} * 1 \mathrm{~mm} * 0.5 \mathrm{~mm}$, as shown in Figure 1.

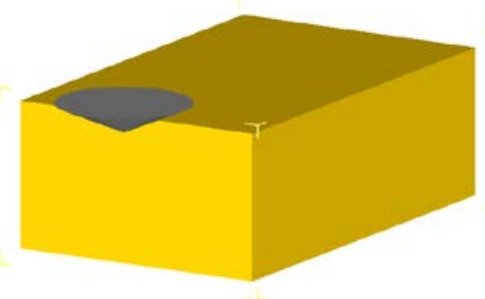

Fig. 1 The simulation geometry model

\section{Setting of simulation technology}

Total time of single particle staying in grinding arc area is only about $0.01 \mathrm{~ms}$, so the workpiece can be regarded as static, and the feed rate of workpiece is 0 . The speed of grinding particle relative to the workpiece and the cutting depth are set according to the needs of the simulation test. In the motion control of the abrasive particle and the workpiece, the movement direction of the abrasive grain is $\mathrm{Y}$ axis and the movement of the workpiece in the three directions is restrained. According to the relative position of the abrasive grains and the workpiece, the $\mathrm{Y}$ axis is equivalent to the tangential direction of the abrasive grains, the $\mathrm{Z}$ axis is equivalent to the normal direction of the abrasive grains, and the $\mathrm{X}$ axis is equivalent to the axial direction of the abrasive grains. Using the finite element mesh to divide the workpiece and the abrasive grains. The workpiece mesh is divided into 34000 units, and the single particle abrasive grain is divided into 1000 units.

\section{Simulation results analysis}

The temperature distribution diagram of the coated wheel and the uncoated grinding wheel is respectively as shown in Fig. 2 and 3. From the picture it can be seen: the grinding temperature of the coating wheel is about 300 degrees lower than that of the uncoated grinding wheel.

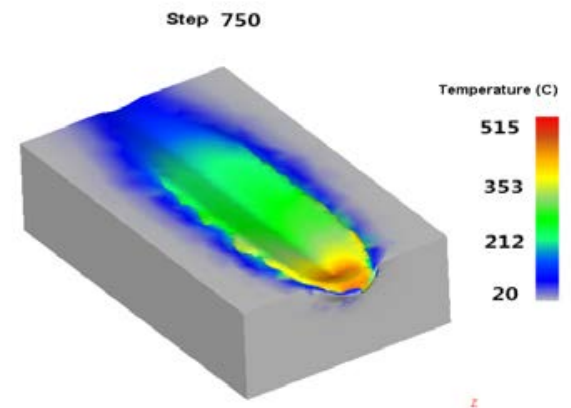

Fig. 2 The temperature distribution diagram of the coated wheel 


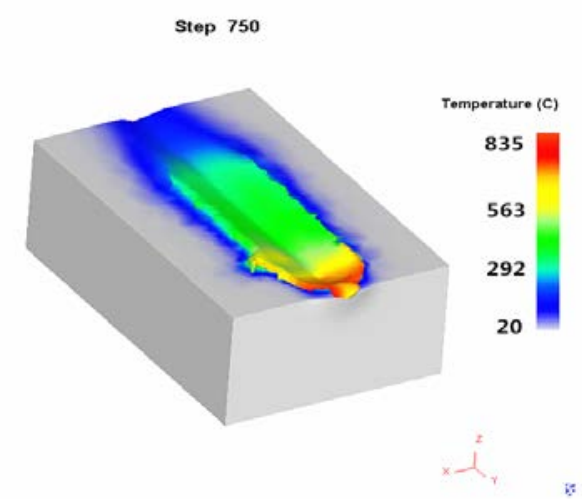

Fig. 3 The temperature distribution diagram of the uncoated wheel

\section{Online electrostatic spraying system}

Studying the intelligent online electrostatic spraying grinding wheel adaptive lubrication coating system through the following methods in this article: (1) analysis of online electrostatic spraying technology, study the form of spray gun, spraying ratio of voltage, the types of nano particles, the ratio of powder, powder flow rate and grinding real-time status, multi-factor coupling coating performance parameters of the calculation, etc; (2) doing experiment of grinding titanium alloy, collecting the grinding temperature, analysis of the changing rule of grinding temperature in grinding process , conclude the characteristics of nano powder coating grinding wheel lubrication.

Compressed air of the direct type solid powder electrostatic spraying device is adopted in this system. Graphite is selected as solid paint, Electrostatic spraying device is composed of controller, powder barrels, lose powder pump, spray gun and so on. Experimental apparatus is shown in Fig. 4. Based on microcosmic research results of nano powder coating bond formation and maintaining mechanism, the general structure of the electrostatic spraying coating system is determined. The intelligent control part and spray gun system of the electrostatic spray coating system are designed, key parts parameters are selected, the multi-parameters controllable adjustable electrostatic spraying coating system are designed and made on the basis.

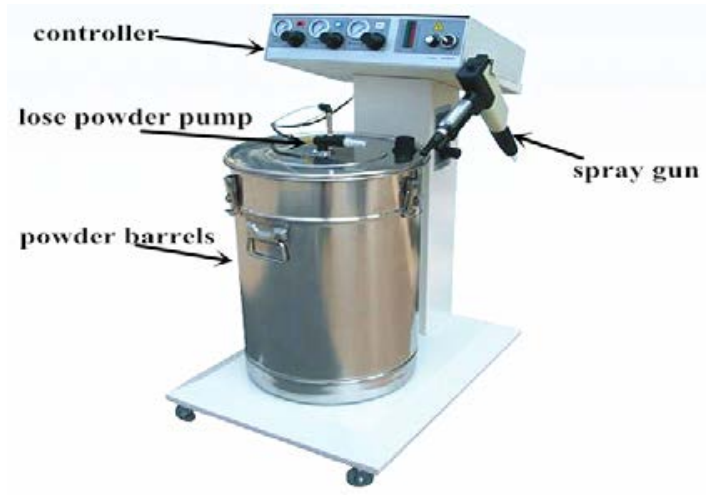

Fig. 4 Electrostatic spraying experimental apparatus

\section{The experiment of grinding temperature measurement}

Adopting $\mathrm{K}$ type thermocouple to measure the grinding temperature in the process of CBN grinding wheel grinding TC4 titanium alloy. The working principle of K type thermocouple: when the two different conductors of the nickel chromium and nickel silicon end into a loop, due to two different kinds of the temperature of the conductor combining site, leads to produce the thermal current in circuit , this physical phenomenon is called setback effect. The temperature measurement system consists of K type thermocouple, charge amplifier, data acquisition card of NI USB6211 and computer, as shown in Fig. 5. Grinding experiments were carried out on a vertical precision milling 
machine, maximum spindle speed of the machine is 3600r / min. Experimental grinding wheel`s outer diameter is $50 \mathrm{~mm}$, and the particle size is 80 mesh. Grinding temperature measurement system physical diagram is shown in Fig. 6.

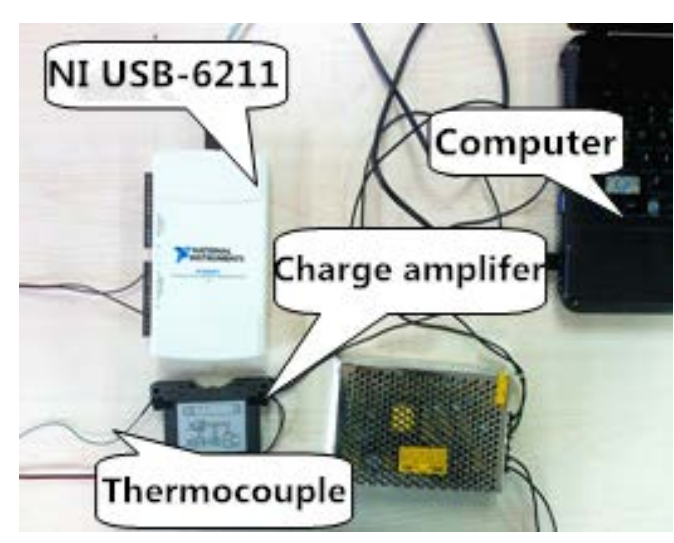

Fig. 5 Temperature measurement system

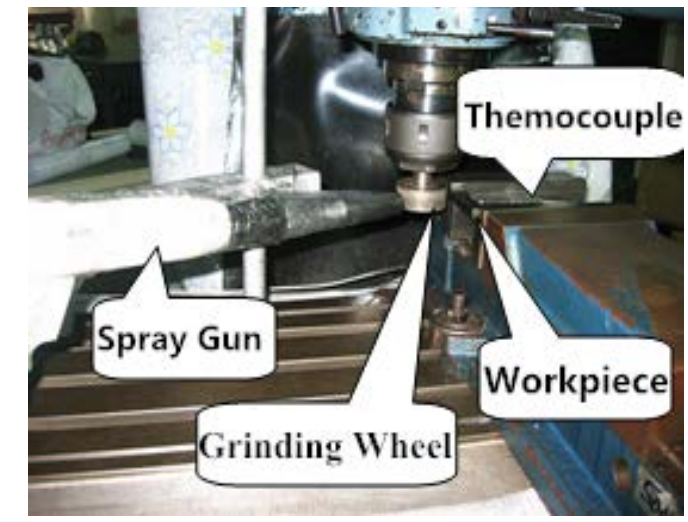

Fig. 6 Temperature measurement system physical diagram

\section{The Experimental Results and Analysis}

If the linear velocity of grinding wheel is under $20 \mathrm{~m} / \mathrm{s}$, the change of grinding temperature on coated CBN grinding wheel and uncoated CBN grinding wheel grinding TC4 titanium alloy are showed as in Fig.7. It is seen from the diagram: as the grinding depth increases, the grinding temperature will gradually increases; The grinding temperature of coated grinding wheel is obviously lower than the uncoated grinding wheel. These can be interpreted as: in the process of dry grinding titanium alloy, the lubrication coating of grinding wheel can play the role of lubrication effectively.

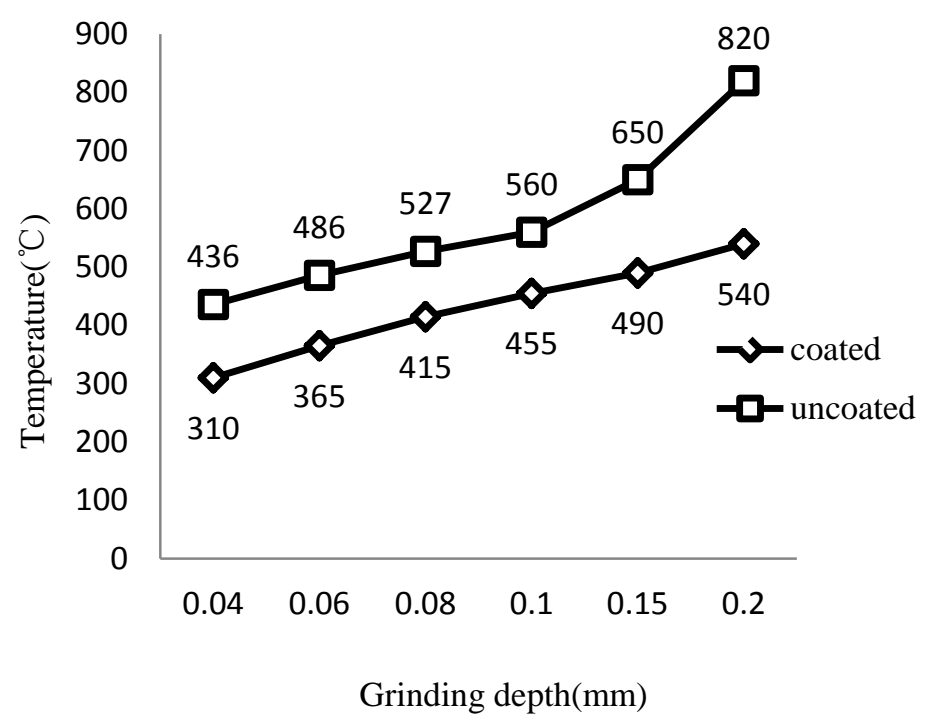

Fig. 7 Temperature changes with grinding depth

\section{Summary}

The simulation results are in line with the real test results, and the simulation model used in this paper can effectively predict the test results and optimize the parameters of the experiment. In the process of dry grinding TC4 titanium alloy, choosing the system of intelligent online electrostatic spraying grinding wheel can obtain homogeneous and continuous coating of grinding wheel. Solid powder coating grinding wheel can reduce the grinding temperature in the process of dry grinding TC4 titanium, to guarantee the surface quality of TC4 titanium alloy and to realize green machining finally. 


\section{Acknowledgments}

This project is supported by National Natural Science Foundation of China (Grant No. 51305301), Tianjin Research Program of Application Foundation and Advanced Technology(Grant No. 14JCQNJC05100), Natural Science Foundation of Guizhou Province of China (Grant No. J[2014]2116) and Innovation Team Training Plan of Tianjin Universities and colleges (Grant No. TD12-5043).

\section{References}

[1] ZHANG Xiyan, ZHAO Yongqing, BAI Chenuang. Titanium alloy and its application[M]. Beijing: Chemical Industry Press, 2005.

[2] HOOD R, LECHNER F, ASPINWALK D K, et al. Creep feed grinding of gamma titanium aluminide and burn resistant [J]. International Journal of Machine Tools \& Manufature,2007, 47 :1486-1492.

[3] REN Jingxin. Grinding technology of difficult-to-machine materials[M].Beijing: National Defense Industry Press, 1999.

[4] HUO Wenguo, XU Jiuhua, FU Yucan, et al. Dry grinding of Ti6AL4V alloy with flap wheels [J]. Transactions of Nations of Nanjing University of Aeronautics \& Astronautics, 2010, 27(2): 131-137.

[5] HUO Wenguo, XU Jiuhua, FU Yucan,QI Huojun, et al. Research status and development of green grinding technology[J].Toolmagzine,2011,45:3-6.

[6] GAO Quanjie, WANG Chaohui, WANG Jiaqing, The discussion on electrostatic spraying technology and its application[J].Modern Paint and Coating,2006,05:39-41. 